\title{
Uncontrolled Generation in Interior Permanent-Magnet Machines
}

\author{
Chong-Zhi Liaw, Student Member, IEEE, Wen L. Soong, Member, IEEE, Brian A. Welchko, Member, IEEE, and \\ Nesimi Ertugrul, Member, IEEE
}

\begin{abstract}
The movement toward higher power automotive electrical systems has spurred research into low-cost alternators capable of operating over a wide constant-power speed range. A promising candidate for this application is a specially designed interior permanent-magnet (IPM) machine operating in uncontrolled generation (UCG). This paper investigates the modeling and performance of IPM machines in UCG. The concept of the voltage-current locus is introduced to explain the presence of hysteresis in the machine stator current and this effect is experimentally demonstrated. The effect of nonidealities such as magnetic saturation and stator resistance are also examined, to achieve a more accurate steady-state and dynamic modeling of the machine behavior. The predictions of these models are tested against experimental results.
\end{abstract}

Index Terms-Interior permanent magnet (IPM), uncontrolled generation (UCG), voltage-current loci.

\section{INTRODUCTION}

\section{A. Background}

A UTOMOTIVE manufacturers are currently looking into low-cost high-power alternators with wide constant-power speed ranges of up to $10: 1$ in order to satisfy the projected needs of next-generation vehicles [1]. A promising means for implementing such an alternator is to use an interior permanent-magnet (IPM) machine operating under uncontrolled generation (UCG), using a switched-mode rectifier to regulate the output voltage. Preliminary experimental results were shown earlier using a specially designed high-flux IPM alternator [2]. This work highlighted the need for a more detailed study of the behavior of IPM machines under UCG operation.

\section{B. $U C G$}

UCG was originally investigated as a fault mode in inverter-driven PM motors [see Fig. 1(a)]. It occurs if the gating signals to the inverter switches are removed when the motor is operating at high speeds where the induced back electromotive

Paper IPCSD-05-016, presented at the 2004 Industry Applications Society Annual Meeting, Seattle, WA, October 3-7, and approved for publication in the IEEE TRANSACTIONS ON INDUSTRY APPLICATIONS by the Electric Machines Committee of the IEEE Industry Applications Society. Manuscript submitted for review October 22, 2004 and released for publication April 25, 2005. This work was supported by the Australian Research Council under Discovery Grant DP0342874.

C.-Z. Liaw, W. L. Soong, and N. Ertugrul are with the Electrical and Electronic Engineering Department, University of Adelaide, Adelaide, SA 5005, Australia (e-mail: chongzhi@eleceng.adelaide.edu.au; wen.soong@ adelaide.edu.au; nesimi.ertugrul@ adelaide.edu.au).

B. A. Welchko is with the General Motors Advanced Technology Center, Torrance, CA 90505 USA (e-mail: bwelchko@ieee.org).

Digital Object Identifier 10.1109/TIA.2005.851557

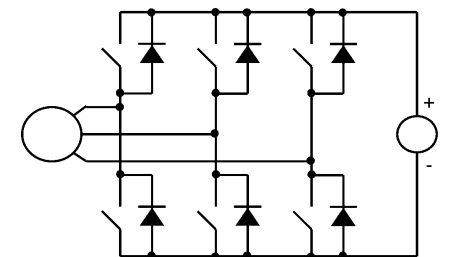

(a)

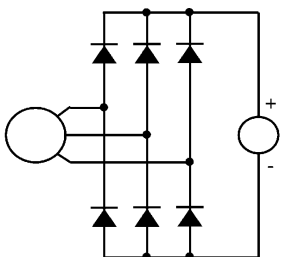

(b)
Fig. 1. (a) Inverter operation-inverter switches are controlled to drive the machine. (b) UCG-with switches disabled at high speed, the machine generates power into the dc voltage source.

force $(E M F)$ exceeds the dc-link voltage. Under this condition, the inverter freewheeling diodes act as an uncontrolled rectifier [see Fig. 1(b)] and the machine generates power into the dc link. This is undesirable due to the potentially large resultant currents, which can cause the dc-bus voltage to rise to high levels if the dc bus is unable to absorb the regenerated power.

Adnanes et al. [3] performed some initial analysis of UCG operation of IPM machines using a time-stepping simulation.

Jahns et al. [4] presented a steady-state model and analysis of UCG operation of IPM machines. It was shown that machines with saliency ratios of greater than 2 will exhibit an interesting hysteresis band in the stator current versus speed characteristic. They also investigated the effect of saturation and showed the hysteresis using a time-stepping simulation.

In this paper, the hysteresis effect predicted in [4] is experimentally demonstrated. In addition, the theoretical basis of the hysteresis is examined using the concept of voltage versus current loci. The steady-state UCG model is extended to take into account stator resistance and magnetic saturation and the model predictions are compared with experimental data taken from two IPM machines. A dynamic model [5] is used to predict transient waveforms and other transient effects present in the IPM machine during UCG operation.

\section{HYSTERESIS IN THEORY}

\section{A. Voltage-Current Loci of IPM Machines}

During UCG operation it can be shown that to a first approximation, the voltage-source load in Fig. 2(a) can be approximated by a resistive load [see Fig. 2(b)], or simplified even further by treating the rectifier and voltage source as a three-phase resistive load [see Fig. 2(c)], [6]. It is helpful to consider the voltage versus current characteristics (VI loci) of an IPM machine operating with a three-phase resistive load.

Fig. 3 shows example VI loci for different machines operating into a resistive load. A dc generator can be modeled by 


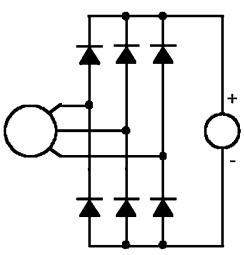

a)

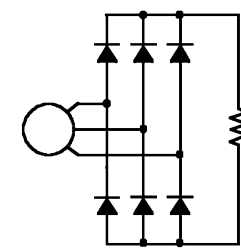

b)

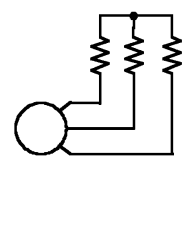

c)

Fig. 2. Various equivalent circuit models for UCG. (a) Rectifier and voltage source. (b) Rectifier and resistive load. (c) Three-phase resistive load.
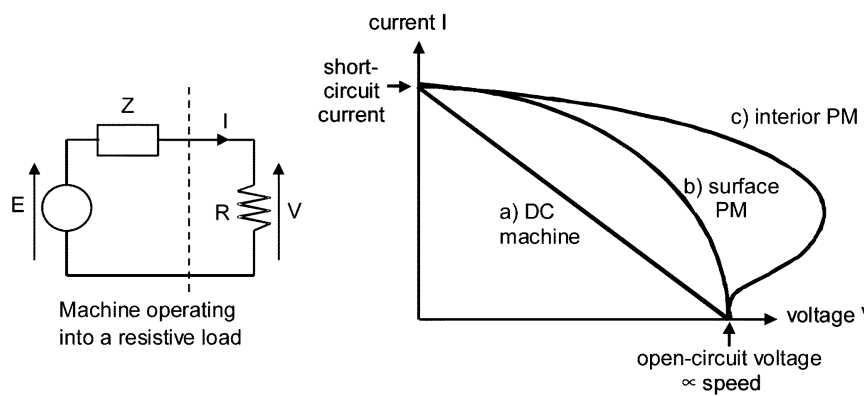

Fig. 3. Electrical circuit model and resultant voltage-current loci for dc surface PM, and IPM machines.

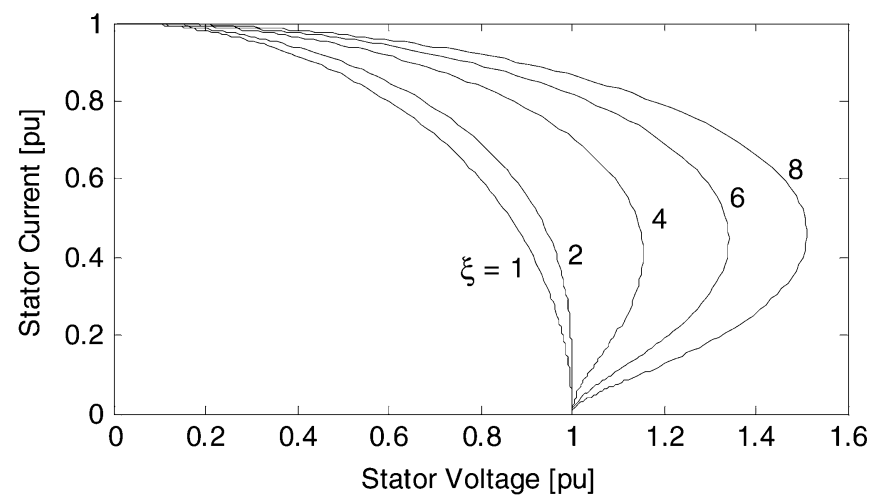

Fig. 4. Effect of saliency on the ideal voltage-current loci of IPM machines.

a dc voltage source with a series resistance. Its VI locus is a straight line $a$ ) which goes from the open-circuit voltage to the short-circuit current. A surface PM machine can be modeled by an ac voltage source and series reactance and it has a semicircular locus $b$ ). A high-saliency-ratio IPM machine can produce a VI locus where the maximum voltage on the locus is higher than the open-circuit voltage $c$ ). This is referred to as voltage "overshoot."

Fig. 4 shows how the shape of the VI locus of an IPM machine changes as a function of saliency ratio. Voltage overshoot occurs with a saliency ratio of greater than 2 , and with greater saliency, there is a larger voltage overshoot.

For example, at a saliency ratio of 6 , which is close to that of the multiple-barrier machine described later in this paper, the voltage overshoot is about $30 \%$ greater than the open-circuit voltage.

\section{B. Hysteresis Effect During UCG}

As the speed increases, both the induced back EMF and the reactances of an IPM machine increase. This results in a linearly increasing open-circuit voltage but a constant short-circuit current (neglecting resistance) as shown in the left graph of Fig. 5.

Fig. 5 can be used to explain how voltage overshoot produces a hysteresis band in the stator current versus speed characteristic under UCG operation. In the left graph, the vertical line represents the stator ac voltage at which the dc output voltage of the rectifier equals the dc-link voltage [see Fig. 2(a)]. Stator currents will only flow when the machine output voltage exceeds this threshold.

For example, consider a case where the machine accelerates from standstill. At a low speed $\omega_{1}$ the machine back EMF is lower than the dc-link voltage, causing the three-phase rectifier to appear as an open circuit $\mathbf{A}$, so no current flows. Conduction only occurs when the open-circuit voltage equals the dc-link voltage at $\omega_{3}(\mathbf{B})$. This operating point is unstable and immediately shifts up the VI locus to operate at $\mathbf{C}$. From there, increasing the speed further to $\omega_{4}$ shifts the operating point to D. Note that current does not start flowing at $\omega_{2}$ because for the machine to produce the voltage at $\mathbf{E}$ there has to be current already flowing.

As the speed is decreased, conduction only ceases when no part of the VI locus intersects with the dc-link voltage line. Thus, decreasing the speed below $\omega_{3}$ does not immediately stop the current from flowing but instead shifts the operating point along the overshoot portion of the VI locus, where the peak machine output voltage is still higher than the dc-link voltage but the current is reduced. At $\omega_{2}$ the peak machine output voltage equals the dc-link voltage $(\mathbf{E})$ and decreasing the speed below this causes conduction to cease.

This illustration shows that the hysteresis in the UCG stator current is caused by voltage overshoot in the VI locus of the IPM machine and that the width of the hysteresis band is proportional to the amount of overshoot. The amount of overshoot is, in turn, determined by the saliency of the machine as shown in Fig. 4.

\section{UCG MODELING}

\section{A. Steady-State UCG Model}

The currents and voltages in an IPM machine can be represented by the phasor diagram in Fig. 6 which is identical to that of a salient-pole synchronous machine. The standard method for analyzing salient-pole synchronous generators starts from knowledge of the magnitudes of the output voltage $V$ and the output current $I$, as well as the phase difference between $V$ and $I$, if any. From these, the rotor angle $\delta$ between the induced voltage $E_{0}$ and $V$, and the magnitude of the induced voltage $E_{0}$ are determined from

$$
\delta=\angle\left(V+j I X_{q}\right), \quad \text { hence } E_{0}=V \cos \delta+I_{d} X_{d}
$$

where the $d$-axis current component $I_{d}=I \sin \delta$.

The steady-state model used by Jahns assumes that the IPM machine phase currents are sinusoidal and free of harmonics during UCG operation and that the rectifier forces the phase currents to be strictly in phase with the phase voltages (as we are using the generator convention). Thus, the three-phase rectifier and voltage-source load [see Fig. 2(a)] can be approximated by a three-phase resistive load [see Fig. 2(c)]. 


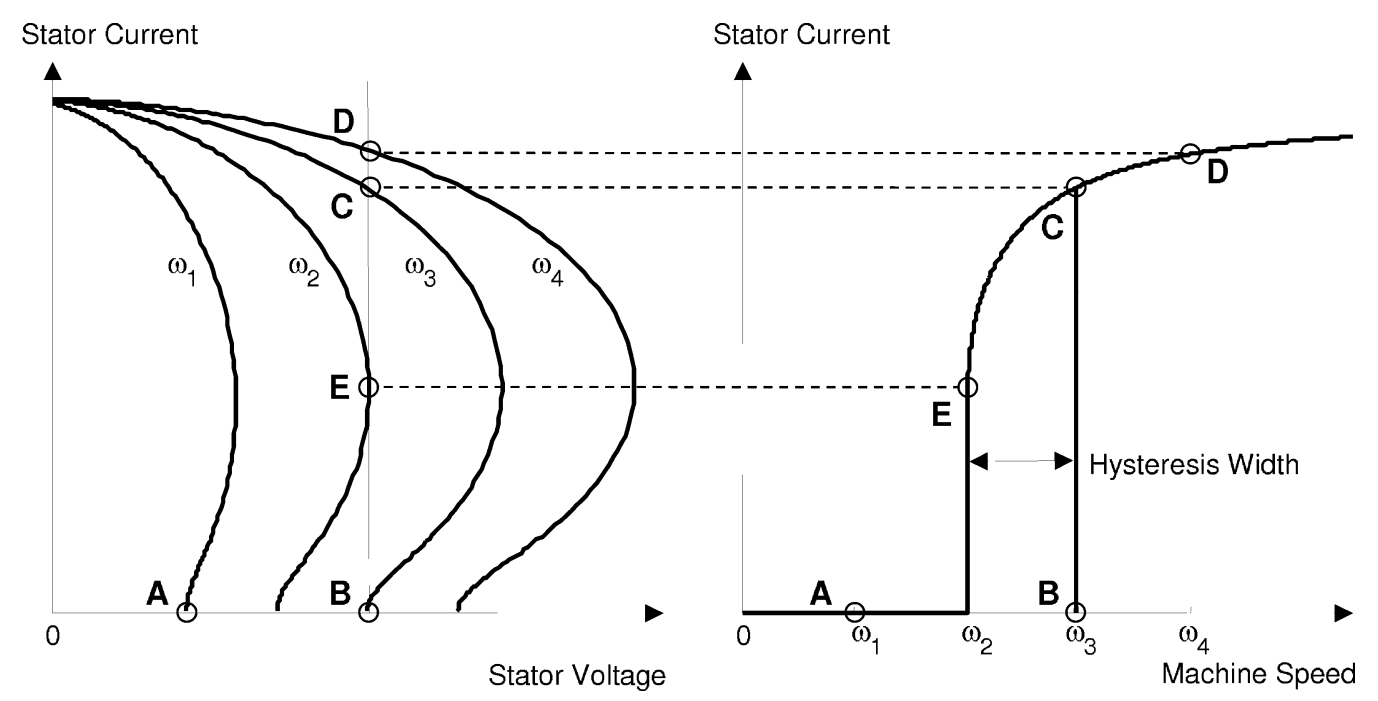

Fig. 5. Relationship between the VI locus and the stator current versus speed graph of an IPM machine exhibiting hysteresis.

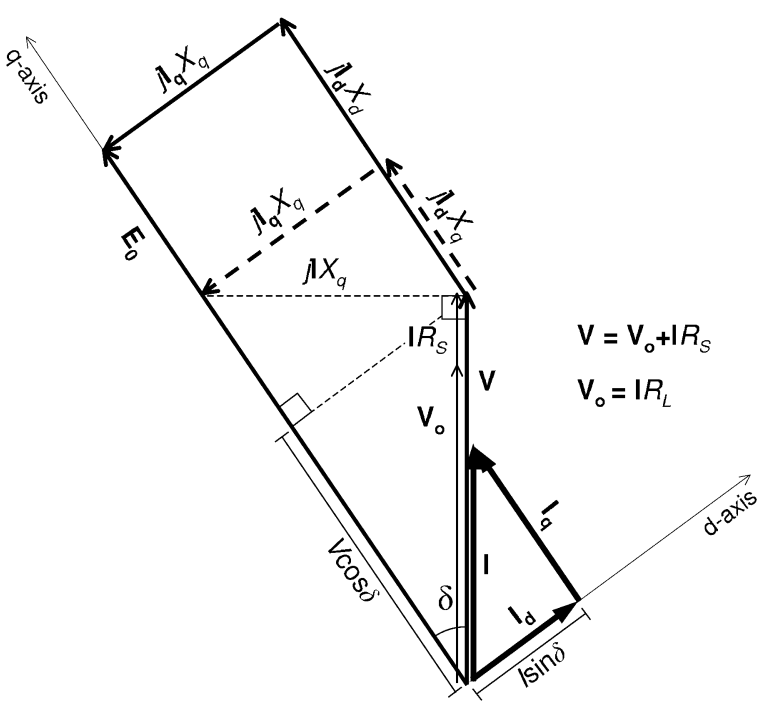

Fig. 6. Phasor diagram for an IPM machine operating into a resistive load using the generator convention.

Jahns' model also assumes that the output voltage (set by the dc-link voltage) during UCG operation and the magnitude of the back EMF $E_{0}$ are known. Note that the back EMF $E_{0}=$ $\Psi_{\text {mag }} \omega_{e}$ where $\Psi_{\text {mag }}$ is the magnet flux linkage and $\omega_{e}$ is the electrical frequency of the machine. From these, the equations can be solved to find the two unknowns: the rotor angle $\delta$ and the current $I$. The stator resistance is assumed to be negligible, which is a valid assumption at the high speeds where UCG normally occurs.

The steady-state model used in this paper retains the assumptions of sinusoidal phase currents and a resistive load but instead of assuming a known output voltage, it uses a known load resistance $R_{L}$. Stator resistance $R_{S}$ can be taken into account by combining it with the load resistance $R_{L}$, so that the machine sees a total resistance of $R_{S}+R_{L}$. The actual output voltage present across the resistive load is $V_{0}=I R_{L}$ but the effective output voltage is $V=I\left(R_{S}+R_{L}\right)$. Thus, $V$ and $I$ are in phase and are related by the resistance $R_{S}+R_{L}$, but neither the magnitude of $V$ or $I$ are known.

To determine the rotor angle $\delta$, the imaginary vector $V+$ $j I X_{q}$ can be used to obtain the following expression for $\delta$ :

$$
\begin{aligned}
\tan \delta & =\frac{I X_{q}}{V}=\frac{I X_{q}}{I\left(R_{L}+R_{S}\right)}=\frac{\omega_{e} L_{q}}{R_{L}+R_{S}} \\
\therefore \delta & =\arctan \left[\omega_{e} L_{q} /\left(R_{L}+R_{S}\right)\right] .
\end{aligned}
$$

To find the current, we can solve (1) for $I$ as follows:

$$
\begin{aligned}
E_{0} & =V \cos \delta+I_{d} X_{d} \\
& =I\left(R_{L}+R_{S}\right) \cos \delta+I \sin \delta \cdot X_{d} \\
\therefore I & =E_{0} /\left[\left(R_{L}+R_{S}\right) \cos \delta+\omega L_{d} \sin \delta\right] .
\end{aligned}
$$

The magnitude of the output voltage $V_{o}$ is then simply

$$
V_{o}=I R_{L}
$$

Magnetic saturation is accounted for by iterating for the $d$-axis inductance $L_{d}\left(I_{d}\right)$ and the $q$-axis inductance $L_{q}\left(I_{q}\right)$ until the values of inductance converge (see Fig. 8).

\section{B. Simulink Dynamic d/q-Axis Model}

The dynamic model used is based on the model developed in [5], which takes into account magnetic saturation and stator resistance. The IPM machine was modeled by the differential equations defining the synchronous frame axis currents $i_{d}$ and $i_{q}$ of the $d / q$ model

$$
\begin{aligned}
& v_{q}=R_{S} i_{q}+L_{q}^{\prime} \frac{d i_{q}}{d t}+\omega_{e} L_{d} i_{d}+\omega_{e} \Psi_{\mathrm{mag}} \\
& v_{d}=R_{S} i_{d}+L_{d}^{\prime} \frac{d i_{d}}{d t}-\omega_{e} L_{q} i_{q}
\end{aligned}
$$

where

$$
L_{q}^{\prime}=L_{q}+\frac{\partial L_{q}}{\partial i_{q}} i_{q} \quad \text { and } \quad L_{d}^{\prime}=L_{d}+\frac{\partial L_{d}}{\partial i_{d}} i_{d}
$$




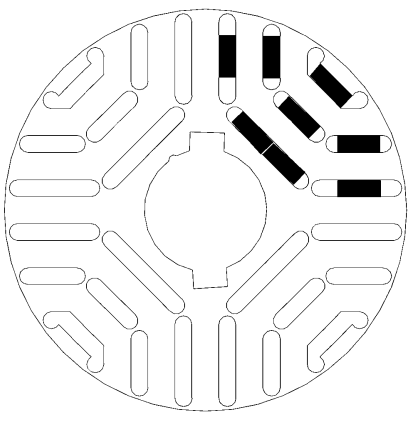

(a)

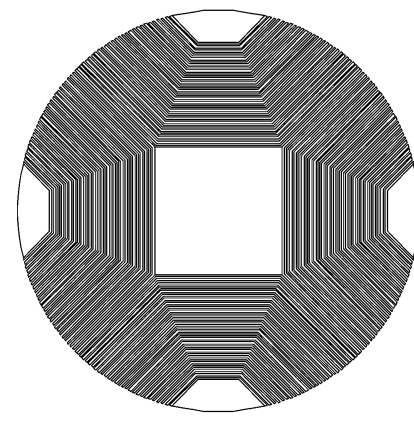

(b)
Fig. 7. Rotor cross sections for (a) the multiple-barrier machine and (b) the axially laminated machine.

TABLE I

MACHINE PARAMETERS

\begin{tabular}{l|c|c}
\hline & Multiple-barrier & Axially laminated \\
\hline$q$-axis inductance (unsat'd) & $312 \mathrm{mH}$ & $340 \mathrm{mH}$ \\
\hline$d$-axis inductance (sat'd) & $53 \mathrm{mH}$ & $45 \mathrm{mH}$ \\
\hline saliency ratio (max) & 5.87 & 7.5 \\
\hline stator phase resistance & $3.0 \Omega$ & $3.0 \Omega$ \\
\hline magnet flux-linkage (Vs peak) & $0.704 \mathrm{Vs}$ & $0.1802 \mathrm{Vs}$ \\
\hline open-circuit line-to-line back- & $271.2 \mathrm{~V}$ & $69.3 \mathrm{~V}$ \\
EMF @ 1500rpm (Vrms) & & \\
\hline short-circuit current @ 1500rpm & $9.4 \mathrm{~A}$ & $2.8 \mathrm{~A}$ \\
\hline max power under UCG operation & $6.8 \mathrm{~kW}$ & $2.0 \mathrm{~kW}$ \\
\hline
\end{tabular}

The model parameters which characterize the machine are the magnet flux linkage, $\Psi_{\text {mag }}$ and the $d$-axis $\left(L_{d}\right)$ and $q$-axis $\left(L_{q}\right)$ inductance saturation curves (see Fig. 8), which have been fitted to the actual inductance measurements.

It was found that magnetic saturation in the $d$ axis has a pronounced effect on the magnitude of the phase currents at low speeds in the multiple-barrier machine and so it was important to take into account.

\section{MACHINE DETAILS AND EXPERIMENTAL SETUP}

Two machines were studied: a multiple-barrier IPM concept demonstrator machine as described in [2] and an axially laminated IPM machine [7]. The multiple-barrier machine has a rotor consisting of radial laminations embedded with rare-earth $(\mathrm{NdFeB})$ magnets while the axially laminated rotor uses flexible ferrite magnets sheets (see Fig. 7). Both rotors used the same $2.2-\mathrm{kW}$ four-pole induction motor stator which was rated at 415 $\mathrm{V}, 4.8 \mathrm{~A}$.

The machine parameters and inductance curves are shown in Table I and Fig. 8. Note that the multiple-barrier machine is capable of a maximum power of nearly $7 \mathrm{~kW}$ under $\mathrm{UCG}$ operation.

The test machines were driven by two $5-\mathrm{kW} 1500-\mathrm{r} / \mathrm{min} \mathrm{dc}$ machines through a belt drive with an adjustable gear ratio, delivering a maximum speed of $6000 \mathrm{r} / \mathrm{min}$ (see Fig. 9). The speed was controlled by varying the dc supply to the dc machines and the reaction torque on the test machine stator was measured using a load cell. The windings of the test machine could be connected to a three-phase rectifier and/or load banks as necessary for each test. For tests involving a dc voltage-source load

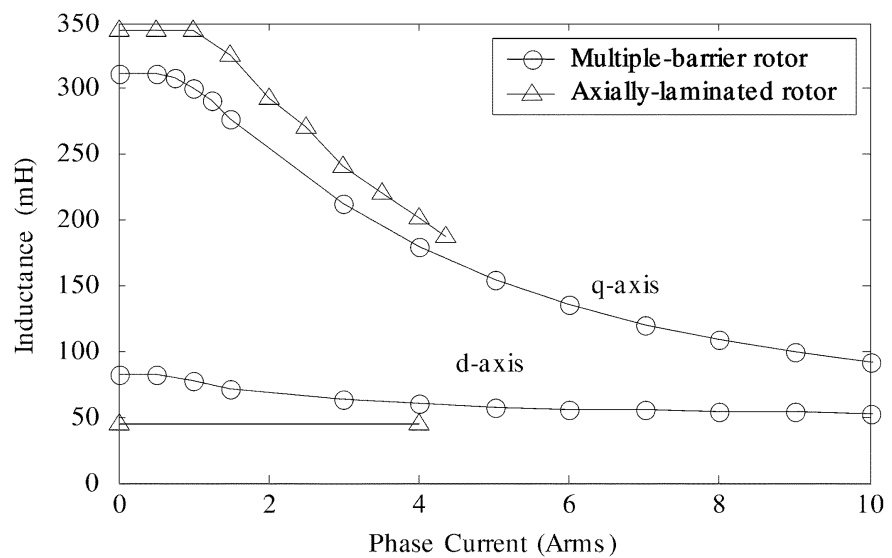

Fig. 8. The measured $d$ - and $q$-axes inductance saturation curves for the multiple-barrier and axially laminated machines.

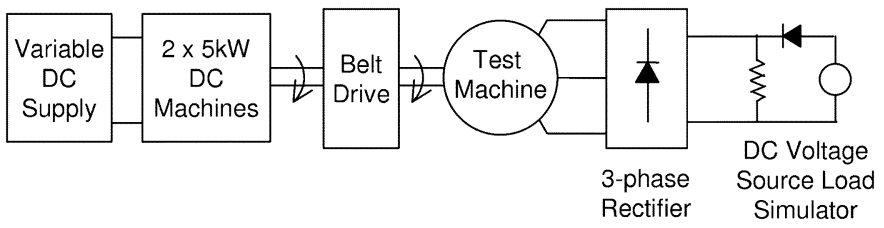

Fig. 9. Block diagram of experimental setup, connected to a three-phase rectifier and voltage source load.
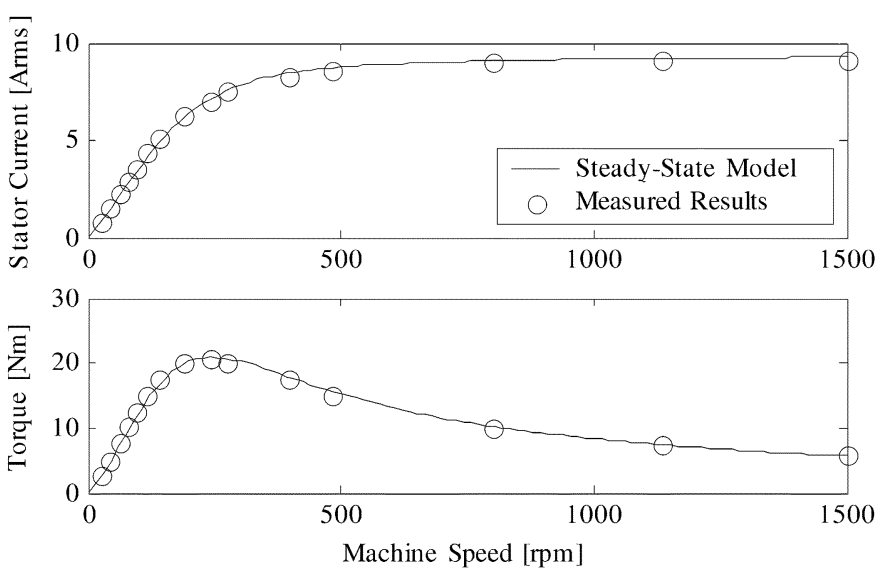

Fig. 10. Short-circuit phase current and torque versus speed for the multiple-barrier machine.

which was required to absorb power, this was simulated using a dc power supply, protective diode, and load bank.

\section{VOLTAGE-CURRENT LOCI}

\section{A. Short-Circuit Test}

Short-circuit tests were performed to verify that the steadystate behavior of the model agreed with the experimental results. These tests were carried out by driving the test machine with the machine's three-phase stator winding short circuited. In this test (see Figs. 10 and 11), the short-circuit current rises monotonically with speed until it reaches a maximum value of $\Psi_{\mathrm{mag}} / L_{d}$. The torque reaches a maximum value at a low speed then gradually decreases with increasing speed.

The calculated curves were obtained from the steady-state model described earlier, using a zero load resistance and the 


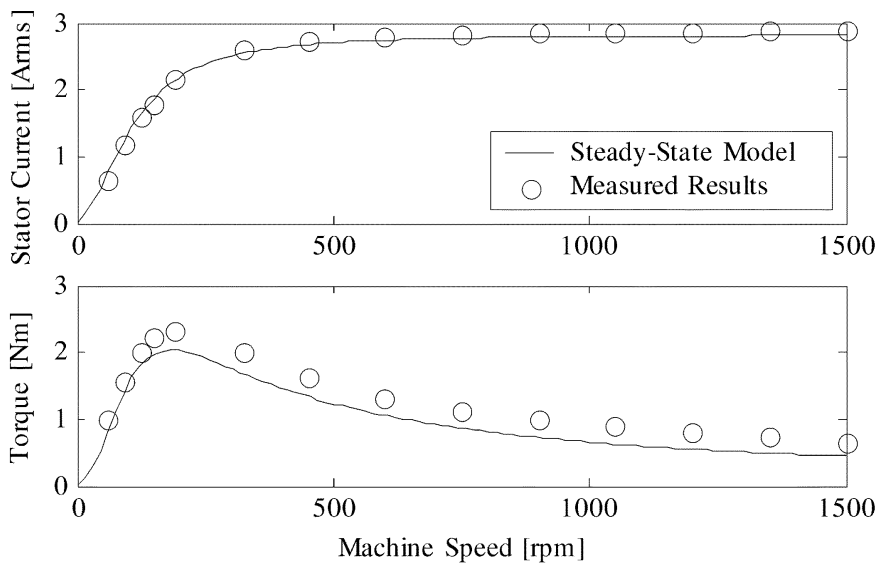

Fig. 11. Short-circuit phase current and torque versus speed for the axially laminated machine.

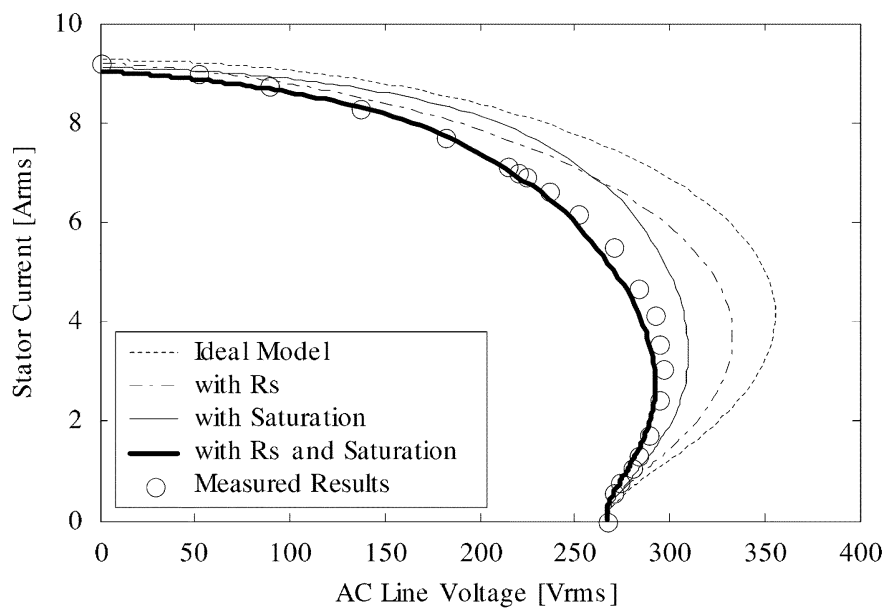

Fig. 12. Voltage-current loci for the multiple-barrier machine, operating at $1500 \mathrm{r} / \mathrm{min}$ with a three-phase resistive load, showing the effect of nonidealities.

measured inductance saturation curves shown in Fig. 8. A good match with the experimental data for the multiple-barrier machine was obtained (see Fig. 10). The measured torque results for the axially laminated machine were slightly larger than the predicted values (see Fig. 11). This may be due to the higher iron losses in this machine or the effect of iron losses being more noticeable in this machine due to the lower input torque.

\section{B. Effect of Stator Resistance and Saturation on the VI Locus}

To investigate the steady-state equivalent circuit model of UCG, the test machines were run at a constant speed of 1500 $\mathrm{r} / \mathrm{min}$ into a three-phase resistive load [see Fig. 2(c)]. The load resistance was varied and a plot of stator current versus line voltage was obtained. The predicted VI loci were obtained from the steady-state model described earlier with the load resistance varied over a wide range of values.

Fig. 12 shows the measured and predicted VI loci for the multiple-barrier machine while operating into the three-phase resistive load. The ideal model prediction shown does not take into account stator resistance or magnetic saturation and shows about $30 \%$ voltage overshoot. The effect of stator resistance alone reduces the overshoot from $30 \%$ to $22 \%$, whereas the effect of magnetic saturation alone reduces the overshoot from $30 \%$ to

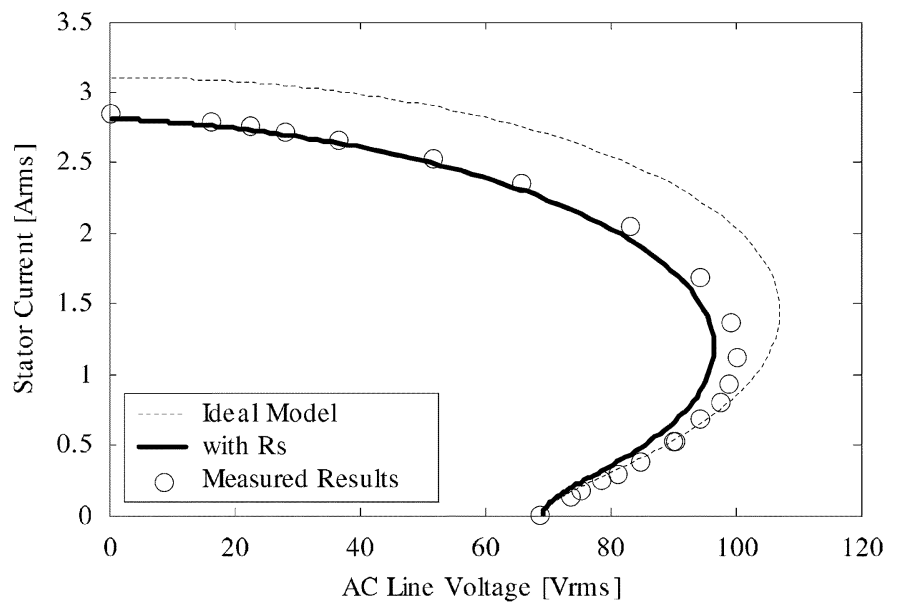

Fig. 13. Voltage-current loci for the axially laminated machine, operating at $1500 \mathrm{r} / \mathrm{min}$ with a three-phase resistive load, showing the effect of nonidealities.

$14 \%$. Thus, for this machine at this speed, the magnetic saturation plays a larger part than stator resistance in reducing the overshoot. The combination of these two effects acts to reduce the overshoot from $30 \%$ to a mere $7 \%$, and the resultant curve matches well with the measured results.

For the axially laminated machine the maximum $q$-axis current produced at $1500 \mathrm{r} / \mathrm{min}$ with any value of the load resistance is about $0.5 \mathrm{~A}$. Referring to Fig. 8, this current is still in the unsaturated region of $L_{q}$, so magnetic saturation can be neglected (see Fig. 13). The decrease in the stator current due to resistance is more noticeable than in the multiple-barrier machine, however, the reduction of overshoot from $56 \%$ greater than the open-circuit voltage to $40 \%$ is less dramatic.

\section{Voltage-Current and Voltage-Power Loci With Rectifier and Resistive Load}

The test machines were run at various speeds into a three-phase rectifier and resistive load [see Fig. 2(b)] and current versus voltage measurements recorded while the load resistance was varied. AC measurements were taken at the machine windings and dc measurements were taken across the resistive load. The dc measurements should give a better indication of the output power delivered to the voltage source load during UCG. The calculated dc voltage and current curves were obtained by scaling the calculated ac voltage and current curves by the factors 1.355 for current (theoretical ratio of rectified dc to the rms ac phase current) and 1.283 for voltage [4], [6].

Fig. 14 shows the measured voltage-current and voltage-power loci together with the steady-state model predictions for the multiple-barrier machine. The ac results match reasonably well with the predicted curves although the current obtained is slightly less than predicted. There is a significant discrepancy, however, in the dc output current and power curves (see Fig. 15) at lower values of current corresponding to the voltage overshoot region. This may be due to the discontinuous current waveforms in this region (see Section VI). The result is a tenfold reduction of the measured overshoot for the multiple-barrier machine at $1500 \mathrm{r} / \mathrm{min}$ from 

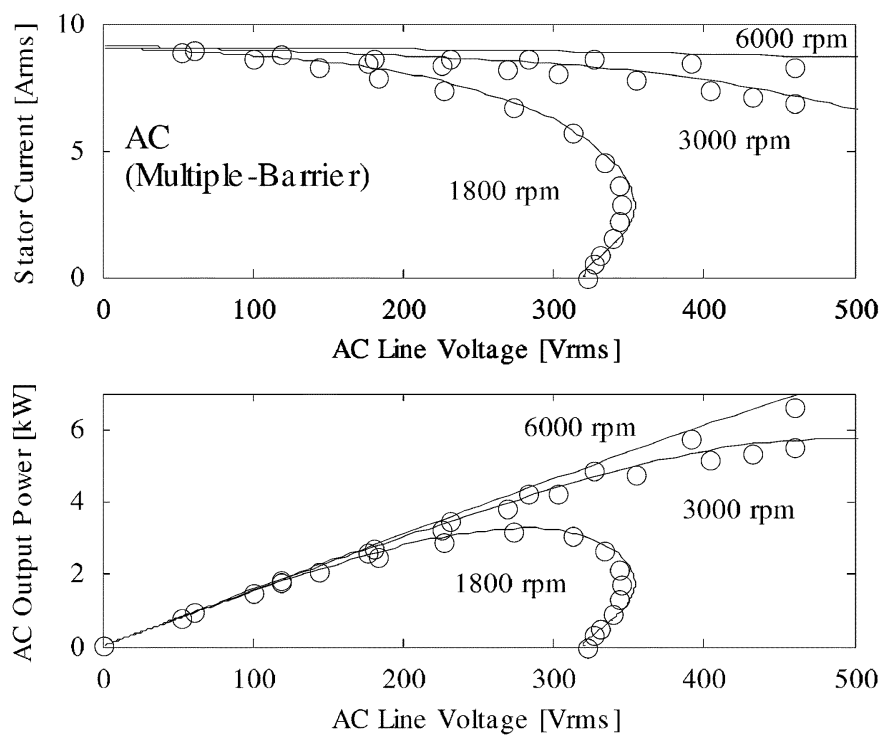

Fig. 14. AC voltage-current and voltage-power loci for the multiple-barrier machine at 1800, 3000, and $6000 \mathrm{r} / \mathrm{min}$, showing calculated results (lines) and measured results (circles).
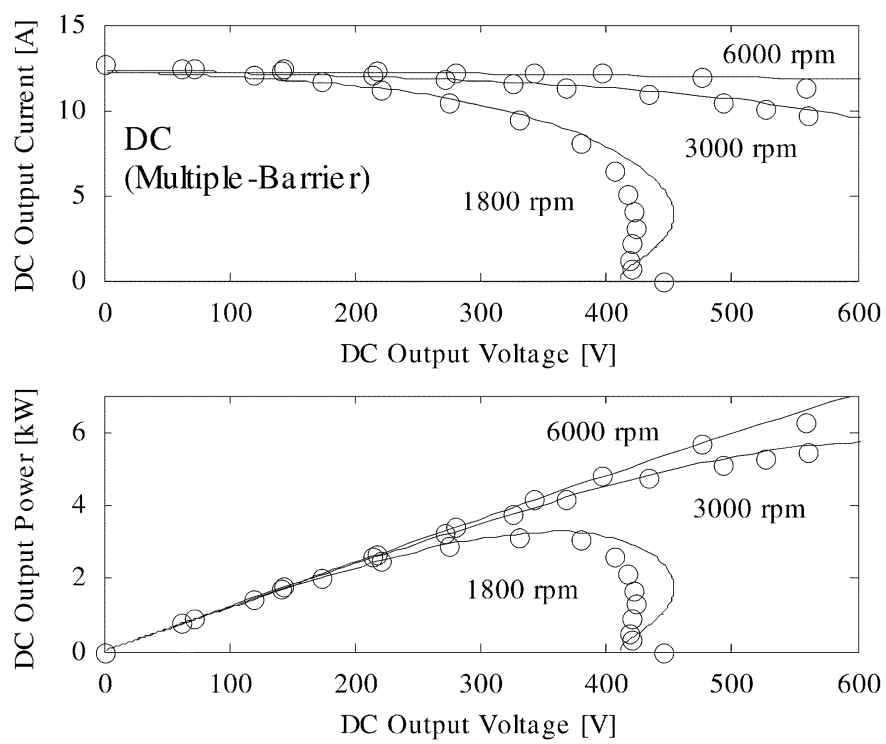

Fig. 15. DC voltage-current and voltage-power loci for the multiple-barrier machine at 1800, 3000, and $6000 \mathrm{r} / \mathrm{min}$, showing calculated results (lines) and measured results (circles).

$10 \%$ greater than the open-circuit voltage for the ac curves to about $1 \%$ for the dc curves.

The multiple-barrier machine results show that at higher speeds the output power is almost linearly related to output voltage and nearly independent of speed. They also show that at rated voltage (415 Vrms) that the machine is capable of producing close to $6 \mathrm{~kW}$ of output power at $6000 \mathrm{r} / \mathrm{min}$.

The results for the axially laminated machine (Figs. 16 and 17) show a good correspondence between the measured and calculated ac curves, but there is again a significant discrepancy in the dc curves. This corresponds to a reduction factor of about 1.7 between the predicted voltage overshoot (39\%) and the measured voltage overshoot $(23 \%)$ in the dc curves. This reduction factor is consistent in both the 750- and 1500-r/min curves.
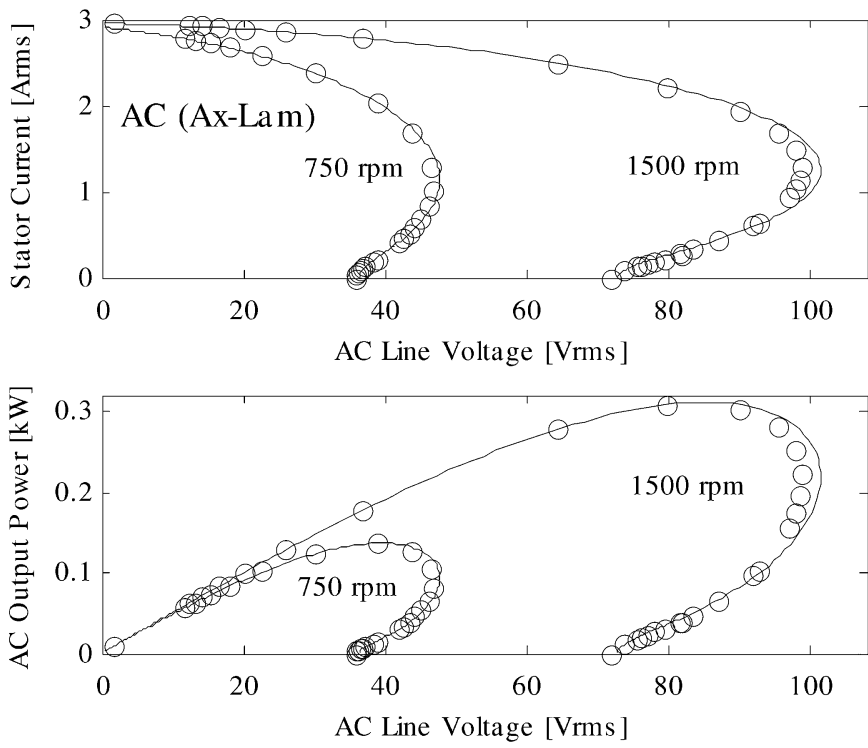

Fig. 16. AC voltage-current and voltage-power loci for the axially laminated machine at 750 and $1500 \mathrm{r} / \mathrm{min}$, showing calculated results (lines) and measured results (circles).
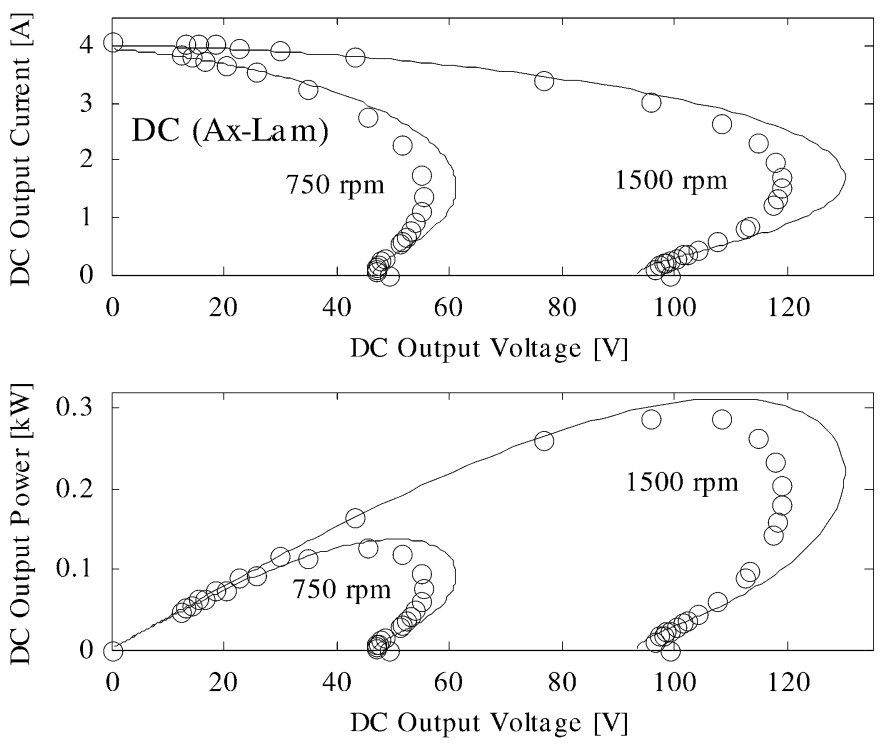

Fig. 17. DC voltage-current and voltage-power loci for the axially laminated machine at 750 and $1500 \mathrm{r} / \mathrm{min}$, showing calculated results (lines) and measured results (circles).

\section{UCG PERFORMANCE}

\section{A. UCG Stator Current Results}

Tests were run with a voltage-source load, configured as described in Section IV. The stator current was measured as the machine speed was increased slowly from standstill up to 1500 $\mathrm{r} / \mathrm{min}$, and then decreased until current stopped flowing.

The multiple-barrier machine was tested operating into a $110-\mathrm{V}$ dc voltage-source load. Referring to the VI loci in Fig. 18, the machine's open-circuit voltage increases with speed but the short-circuit stator current generally stays constant. The exception is at low speeds, where the stator reactance of the machine is small enough that the resistance dominates, causing the VI locus of the machine to resemble that of a dc machine (see Fig. 3). The vertical line overlaid on the VI loci represents 

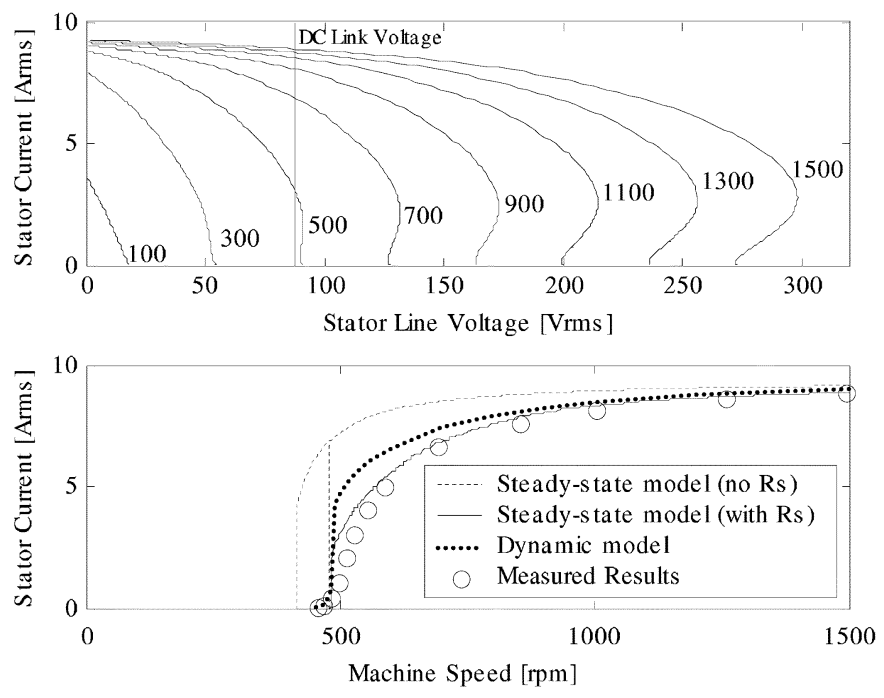

Fig. 18. Predicted and measured hysteresis in the UCG stator phase current for the multiple-barrier machine operating into a $110-\mathrm{V}$ dc voltage source.
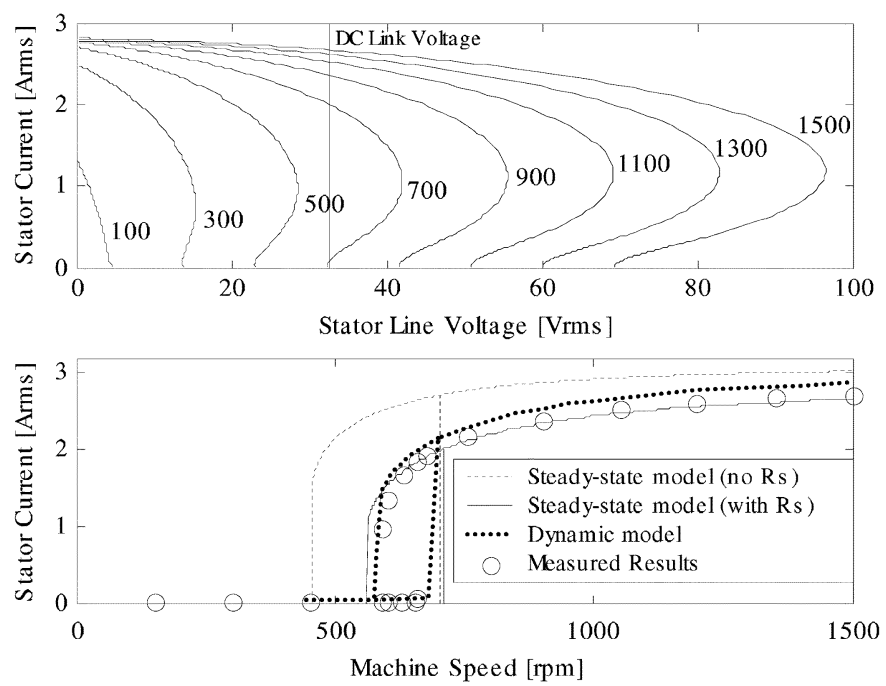

Fig. 19. Predicted and measured hysteresis in UCG stator phase current for the axially laminated machine operating into a $40-\mathrm{V}$ dc voltage source.

the $110-\mathrm{V}$ dc voltage source load referred to the machine. No hysteresis was observed in the multiple-barrier machine because where conduction starts, at around $480 \mathrm{r} / \mathrm{min}$, there is virtually no voltage overshoot in the VI locus.

The axially laminated machine was tested operating into a $40 \mathrm{~V}$ dc voltage source load (see Fig. 19). It exhibited a $15 \%$ hysteresis band which is significantly smaller than the steadystate prediction including resistance of $25 \%$, but closer to the dynamic model prediction of $18 \%$.

For both machines, the steady-state model with stator resistance and the dynamic model predictions provide a reasonable match with the experimental results. The steady-state model prediction neglecting stator resistance overestimates the hysteresis band. This is because stator resistance decreases the voltage overshoot and thus the hysteresis band. This model also overestimates the stator current at low speeds, where resistance is a significant factor.

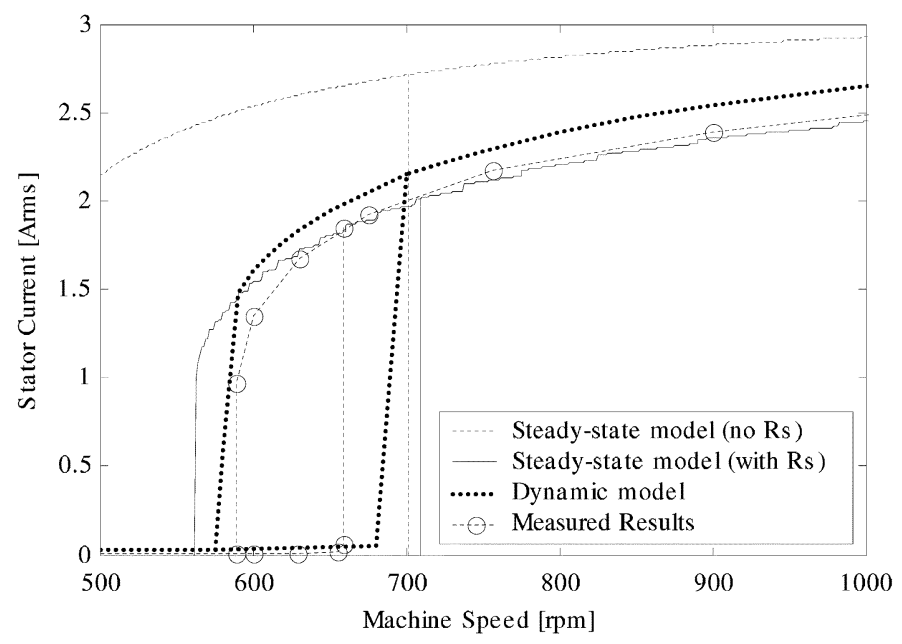

Fig. 20. Enlarged view of the hysteresis band shown in Fig. 19.

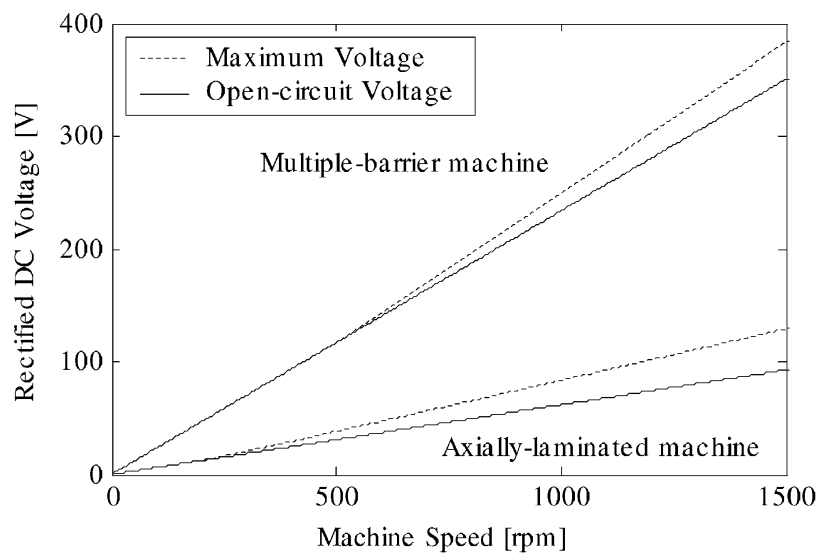

Fig. 21. Rectified open-circuit voltage and rectified maximum machine output voltage versus machine speed including the effect of saturation and stator resistance.

The dynamic model provides a closer match with the starting and ending points of conduction (see Fig. 20). This may be due to the three-phase rectifier, which at low speeds causes the stator currents to be discontinuous. This effect is not taken into account by the steady-state model.

\section{B. UCG Hysteresis Band as a Function of DC-Link Voltage}

Figs. 18 and 19 have shown how the IPM machine VI locus scales with machine speed. Fig. 21 shows the equivalent rectified dc voltage as a function of speed, produced by each machine at open-circuit, and with a load corresponding to maximum output voltage. The effect of stator resistance and magnetic saturation are taken into account. Fig. 21 predicts that hysteresis will not occur below a certain dc-link voltage threshold. This threshold is the rectified dc voltage that the machine produces at the speed where voltage overshoot first appears. This corresponds to the speed at which the maximum voltage is first greater than the open-circuit voltage. For instance, in the case of the multiple-barrier machine, this threshold voltage is approximately $115 \mathrm{~V}$.

Figs. 22 and 23 show the UCG hysteresis band as a function of dc-link voltage, calculated with the method shown in Fig. 21 using the steady-state model with and without stator resistance. 


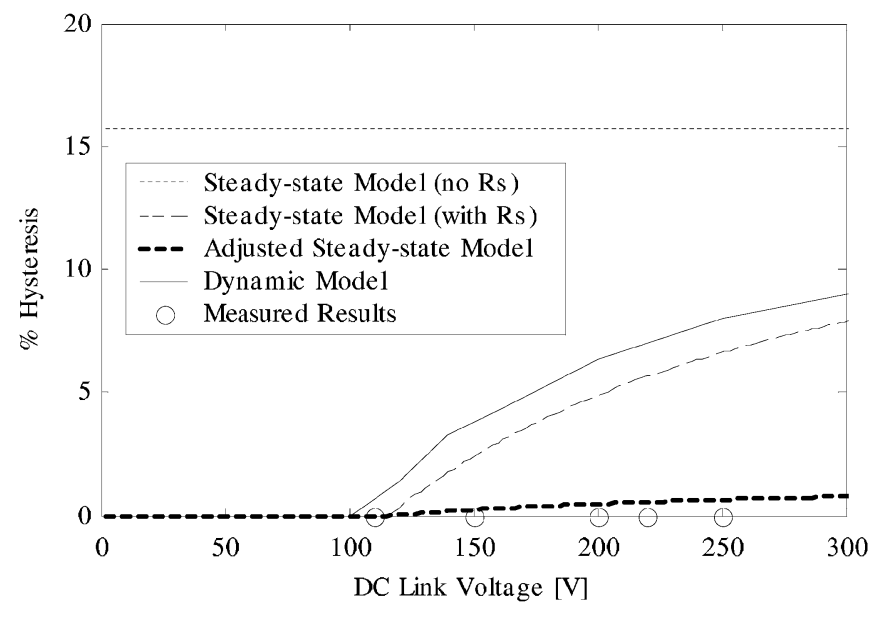

Fig. 22. Model predictions and measured hysteresis band as a function of the dc-link voltage for the multiple-barrier machine.

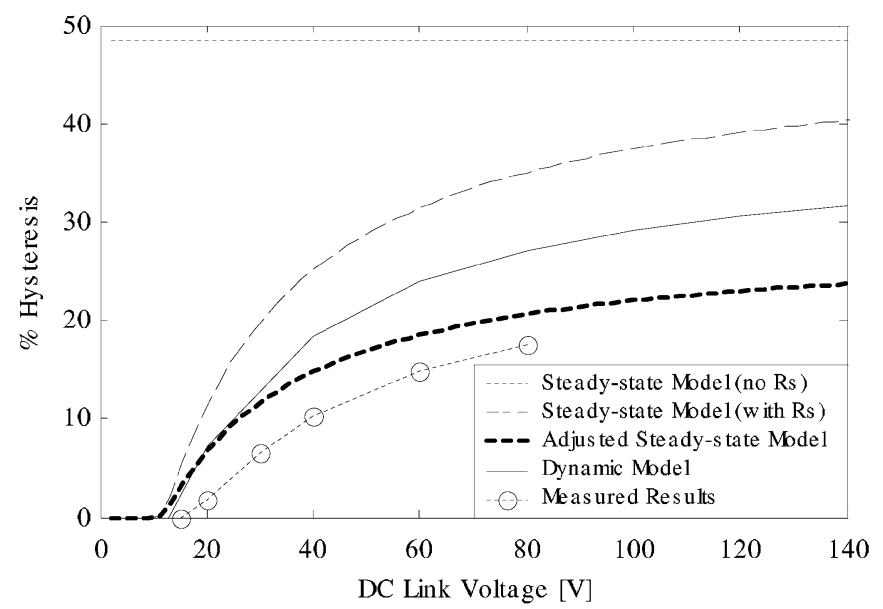

Fig. 23. Model predictions and measured hysteresis band as a function of the dc-link voltage for the axially laminated machine.

These two results are compared against experimental results and the prediction from the dynamic model. All the models took into account the effect of saturation.

The steady-state model neglecting stator resistance (horizontal fine dashed line) predicts that the machines should ideally exhibit a constant hysteresis band of $16 \%$ for the multiple-barrier machine and $48 \%$ for the axially laminated machine.

The steady-state model including stator resistance (coarse dashed line) shows that no hysteresis is predicted for dc-link voltage below the thresholds of $115 \mathrm{~V}$ for the multiple-barrier machine and $11 \mathrm{~V}$ for the axially laminated machine. At dc-link voltages above these thresholds, a reduced hysteresis band is obtained, which asymptotes toward the ideal hysteresis band value as the dc-link voltage increases.

The dynamic model (solid line) predicts a lower value of hysteresis band than the steady-state model including resistance for the axially laminated machine but a larger value of hysteresis band for the multiple-barrier machine. The reason for this requires more investigation.

The experimental results for the axially laminated machine show a good correspondence with the prediction for the dc-link voltage where hysteresis first starts to appear, however the measured rate of increase of the hysteresis band with dc-link voltage is significantly smaller than both the steady-state and dynamic model predictions.

For the multiple-barrier machine, the expected dc-link voltage threshold was $115 \mathrm{~V}$ but no hysteresis was observed experimentally even up to dc-link voltages of $250 \mathrm{~V}$.

These deviations in the hysteresis band from the predictions are likely to be due to the reduced overshoot in the measured dc voltage-current loci compared to the ac model prediction. In Section $\mathrm{V}$ this was experimentally found to be a factor of 10 for the multiple-barrier machine and a factor 1.7 for the axially laminated machine. By reducing the predicted hysteresis band by this factor the 'adjusted steady-state model' curves (heavy dashed line) were obtained. These adjusted curves show a much closer correspondence to the experimental results. For the multiple-barrier machine, the predicted hysteresis may now be too small to detect with the existing experimental set-up.

The adjusted curves show that while the steady-state model can accurately predict the ac voltage-current loci of the machines, the reduction in overshoot observed in the dc voltage-current loci in Section V can have the effect of significantly reducing the actual hysteresis band.

\section{UCG Current Waveforms}

Fig. 24 compares the measured multiple-barrier machine's stator current and voltage waveforms with the dynamic model predictions at various speeds when operating with a rectifier and voltage source load. At high speed $(1500 \mathrm{r} / \mathrm{min})$ where the back-EMF voltage is much higher than the dc-link voltage, the stator current is sinusoidal while the stator line voltage is similar to that from a six-step inverter. As the speed is reduced, the back-EMF becomes comparable to the dc-link voltage. The current waveform then becomes discontinuous and the stator voltage waveform transitions become less steep.

The dynamic model performs well in predicting the voltage and current waveforms, even at the start of conduction (482 $\mathrm{r} / \mathrm{min}$ ). The low-amplitude high-frequency oscillations in the prediction at $482 \mathrm{r} / \mathrm{min}$ is an artefact of the simulation process. At $504 \mathrm{r} / \mathrm{min}$, the predicted current waveform has a slightly smaller magnitude than the measured waveform. This is likely to be due to the high sensitivity of the dynamic model to errors in the inductance curve fit, particularly for the current at this speed, where the slope of the $d$-axis inductance versus $d$-axis current curve is steep.

\section{Steady-State Output Power}

Fig. 25 shows the maximum generating power of the multiple-barrier machine while operating under UCG using a switched-mode rectifier as described in [8]. The high-power automotive alternator output specification of 4 and $6 \mathrm{~kW}$ at engine speeds of 600 and $6000 \mathrm{r} / \mathrm{min}$, respectively, is also shown (note that the alternator speed $=$ engine speed $\times 3: 1$ belt ratio). Experimental results were only measured up to $6000 \mathrm{r} / \mathrm{min}$ due to the limitations of the dynamometer, though the prototype rotor had an estimated failure speed of $12-15 \mathrm{kr} / \mathrm{min}$.

The measured results match the steady-state model predictions well. The machine achieves about $6.6 \mathrm{~kW}$ at $6000 \mathrm{r} / \mathrm{min}$. 

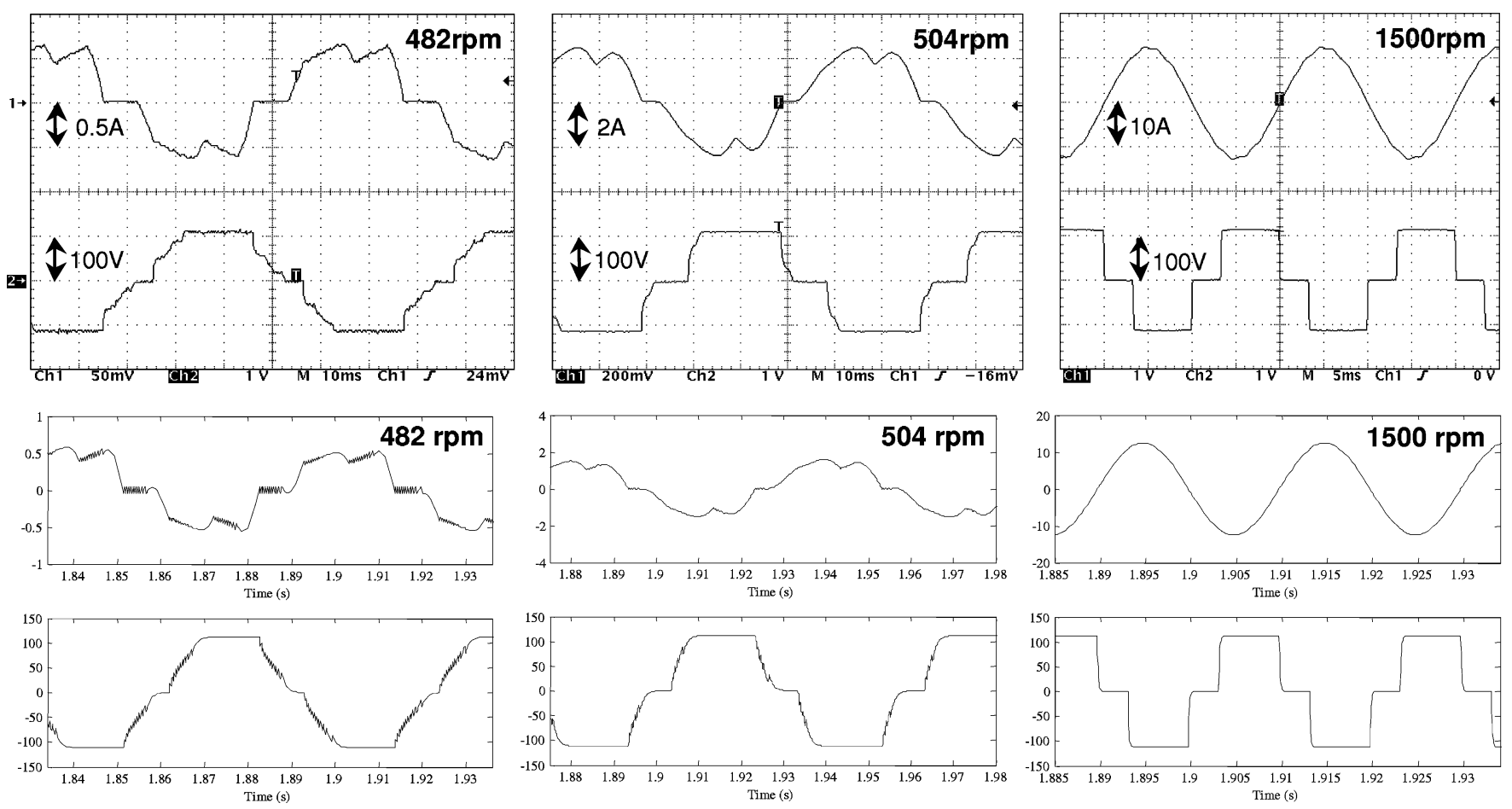

Fig. 24. Measured versus predicted UCG waveforms from the dynamic model of stator current and voltage for the multiple-barrier rotor at speeds corresponding to the start of conduction, at a low speed after the conduction point and at high speed. A dc-link voltage of $110 \mathrm{~V}$ was used.

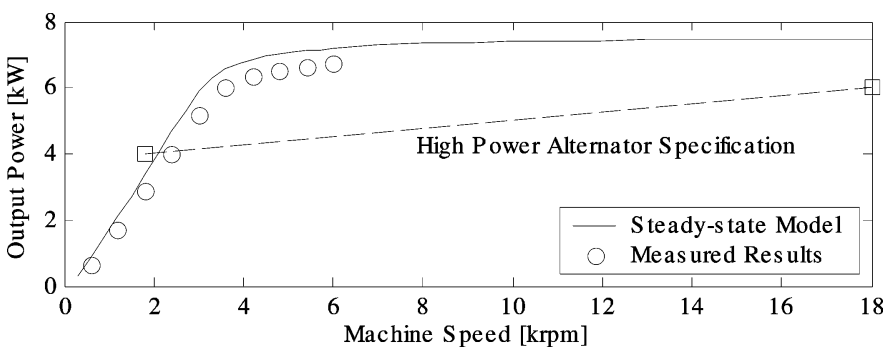

Fig. 25. Multiple-barrier machine output power versus speed, while operating under UCG with a switched-mode rectifier into a $200-\mathrm{V}$ dc voltage source load. The high-power alternator specification is also shown for comparison.

These initial results show promise for the use of UCG to achieve a wide constant-power speed range in IPM alternators.

\section{CONCLUSION}

This paper has investigated the modeling and performance of IPM machines under UCG operation. The main findings of the paper are as follows.

- The output voltage versus current locus of high-saliency IPM machines with a three-phase resistive load show a voltage overshoot effect where the output voltage under load is greater than the open-circuit voltage.

- This voltage overshoot is responsible for the hysteresis in the UCG stator current versus speed characteristic and the width of the hysteresis band is proportional to the voltage overshoot.

- Magnetic saturation and stator resistance reduce the voltage overshoot and, hence, the hysteresis. The effect of stator resistance is particularly pronounced at low speeds, but is small at high speeds.
- Neglecting stator resistance, the hysteresis band is independent of dc-link voltage. Including stator resistance reduces the hysteresis band at all dc-link voltages, but this effect is particularly pronounced for smaller values of dc-link voltage and reduces the hysteresis band to zero at very low values of dc-link voltage.

- Experimental results were given for two high-saliency IPM machines, showing UCG operation with hysteresis and without hysteresis.

- The steady-state model including magnetic saturation and stator resistance was found to accurately predict the voltage overshoot with a three-phase resistive load but showed significant errors with a rectifier/voltage-source load. This caused the magnitude of the hysteresis band to be significantly overestimated, particularly for the multiple-barrier machine.

- The dynamic model was found to accurately predict the stator voltage and current waveforms even under discontinuous current operation.

- Experimental results demonstrate that an IPM alternator operating under UCG has the potential to produce high output power over a wide constant-power speed range.

Future work could include a more detailed investigation into the effect of the reduced voltage overshoot in the dc voltage-current loci in Section V.

\section{ACKNOWLEDGMENT}

The authors gratefully acknowledge the technical support from D. M. Whaley and the staff of the School of Electrical and Electronic Engineering's mechanical workshop during the experimental testing at the University of Adelaide. 


\section{REFERENCES}

[1] J. G. Kassakian, "Automotive electrical systems-the power electronics market of the future," in Proc. IEEE APEC'00, vol. 1, Feb. 2000, pp. 3-9.

[2] W. L. Soong and N. Ertugrul, "Inverterless high power interior permanent magnet automotive alternator," IEEE Trans. Ind. Appl., vol. 40, no. 4, pp. 1083-1091, Jul./Aug. 2004.

[3] A. K. Adnanes, R. Nilssen, and R. O. Rad, "Power feed-back during controller failure in inverter fed permanent magnet synchronous motor drives with flux-weakening," in Proc. IEEE PESC'92, 1992, pp. 958-963.

[4] T. M. Jahns and V. Caliskan, "Uncontrolled generator operation of interior PM synchronous machines following high-speed inverter shutdown," IEEE Trans. Ind. Appl., vol. 35, no. 6, pp. 1347-1357, Nov./Dec. 1999.

[5] B. A. Welchko, T. M. Jahns, W. L. Soong, and J. M. Nagashima, "IPM synchronous machine drive response to symmetrical and asymmetrical short circuit faults," IEEE Trans. Energy Convers., vol. 18, no. 2, pp. 291-298, Jun. 2003.

[6] V. Caliskan, D. J. Perreault, T. M. Jahns, and J. G Kassakian, "Analysis of three-phase rectifiers with constant-voltage loads," IEEE Trans. Circuits Syst. I, Fundam. Theory Appl., vol. 50, no. 9, pp. 1220-1225, Sep. 2003.

[7] W. L. Soong and N. Ertugrul, "Field-weakening performance of interior permanent magnet motors," IEEE Trans. Ind. Appl., vol. 38, no. 5, pp. 1251-1258, Sep./Oct. 2002.

[8] C. Z. Liaw, D. M. Whaley, W. L. Soong, and N. Ertugrul, "Investigation of inverterless control of interior permanent magnet alternators," in Conf. Rec. IEEE-IAS Annu. Meeting, Seattle, WA, Oct. 2004, pp. 276-283.

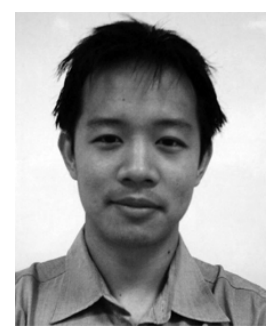

Chong-Zhi Liaw (S'04) received the B.Eng. degree in 2003 from the University of Adelaide, Adelaide, Australia, where he is currently working toward the Ph.D. degree.

His present research interests include permanentmagnet machines and control systems.

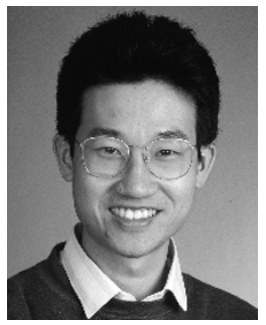

Wen L. Soong (S'89-M'90) was born in Kuala Lumpur, Malaysia. He received the B.Eng. degree from the University of Adelaide, Adelaide, Australia, in 1989, and the Ph.D. degree from the University of Glasgow, Glasgow, U.K., in 1993.

For four years, he was an Electrical Engineer in the Power Controls Program at General Electric Corporate Research and Development, Schenectady, NY, before taking up a teaching position in the Electrical and Electronic Engineering Department at the University of Adelaide in 1998. His present research interests include permanent-magnet and reluctance machines, renewable energy generation, magnetic levitation, and condition monitoring and diagnostics.

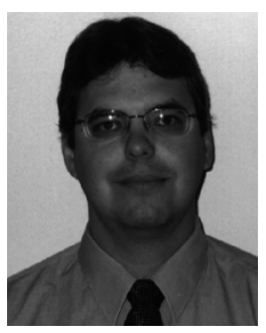

Brian A. Welchko (S'98-M'04) received the B.S. and M.S. degrees from Ohio University, Athens, in 1994 and 1996, respectively, and the Ph.D. degree from the University of Wisconsin, Madison, in 2003, all in electrical engineering.

In 2004, he joined the General Motors Advanced Technology Center (GMATC), Torrance, CA, where he works on various projects in the advanced development group. His current research interests are in novel power converter topologies and control methods applied to interior permanent-magnet synchronous machines for hybrid and fuel-cell-powered vehicles.

Dr. Welchko is a Member of the IEEE Industry Applications, IEEE Power Electronics, IEEE Industrial Electronics, and IEEE Power Engineering Societies. He is also a Member of the European Power Electronics Society and served as the Technical Program Co-Chair for the 2003 IEEE International Electric Machines and Drives Conference (IEMDC), which was held in Madison, WI.

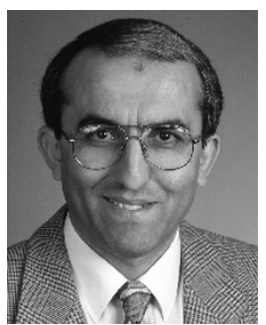

Nesimi Ertugrul (M'95) received the B.Sc. in electrical engineering and the M.Sc. degree in electronic and communication engineering from Istanbul Technical University, Istanbul, Turkey, in 1985 and 1989, respectively, and the Ph.D. degree from the University of Newcastle upon Tyne, Newcastle upon Tyne, U.K., in 1993.

Since 1994, he has been with Adelaide University, Adelaide, Australia, where he is a Senior Lecturer. His primary research topics include sensorless operation of switched motors, fault-tolerant motor drives, condition monitoring, and electric vehicles. He is the author of LabVIEW for Electric Circuits, Machines, Drives and Laboratories (Upper Saddle River, NJ: Prentice-Hall, 2002).

Dr. Ertugrul serves on the Editorial Advisory Board of the International Journal of Engineering Education. 